\title{
Inclined Lidar Observations of Boundary Layer Aerosol Particles above the Kongsfjord, Svalbard
}

\author{
Astrid LAMPERT $^{1}{ }^{*}$, Johan STRÖM ${ }^{2,5}$, Christoph RITTER ${ }^{1}$, \\ Roland NEUBER ${ }^{1}$, Young Jun YOON ${ }^{3}$, Nam Yi CHAE ${ }^{3}$, \\ and Masataka SHIOBARA ${ }^{4}$
}

${ }^{1}$ Alfred Wegener Institute for Polar and Marine Research, Potsdam, Germany e-mail: Astrid.Lampert@tu-bs.de

${ }^{2}$ Norwegian Polar Institute, Framsenteret, Tromsø, Norway

${ }^{3}$ Korea Polar Research Institute, Get Pearl Tower, Incheon City, Korea

${ }^{4}$ National Institute of Polar Research, Tokyo, Japan

${ }^{5}$ Department of Applied Environmental Science, Stockholm University, Sweden

* Now at Institute of Aerospace Systems,

Technische Universität Braunschweig, Braunschweig, Germany

\section{Abstract}

An inclined lidar with vertical resolution of $0.4 \mathrm{~m}$ was used for detailed boundary layer studies and to link observations at Zeppelin Mountain $(474 \mathrm{~m})$ and Ny-Ålesund, Svalbard. We report on the observation of aerosol layers directly above the Kongsfjord. On 29 April 2007, a layer of enhanced backscatter was observed in the lowest $25 \mathrm{~m}$ above the open water surface. The low depolarization ratio indicated spherical particles. In the afternoon, this layer disappeared. The ultrafine particle concentration at Zeppelin and Corbel station (close to the Kongsfjord) was low. On 1 May 2007, a drying process in the boundary layer was observed. In the morning, the atmosphere up to Zeppelin Mountain showed enhanced values of the backscatter coefficient. Around noon, the top of the highly 
reflecting boundary layer decreased from 350 to $250 \mathrm{~m}$. The top of the boundary layer observed by lidar was confirmed by radiosonde data.

Key words: Arctic boundary layer, lidar, aerosol, Svalbard.

\section{INTRODUCTION}

The Arctic atmospheric boundary layer (ABL) has special properties and it is therefore difficult to represent it in climate models. Unique features include the very shallow surface layer, of a depth of only few hundred or even tens of meters (Paluch et al. 1997, Tjernström 1999, 2005). This is a result of the stably stratified atmosphere which often develops above ice and snow covered surfaces, characterized by a strong temperature, and frequently also a moisture inversion (Curry et al. 1988, Brümmer et al. 1994, Beesley et al. 2000, Vihma et al. 2003, Vogelmann et al. 2003). In contrast, small-scale turbulence and convection create a higher mixed boundary layer above open water (Dare and Atkinson 2000).

Another phenomenon in the Arctic is the long lifetime of aerosol in the winter and spring boundary layer (Treffeisen et al. 2007, Tomasi et al. 2007). Due to the stable thermal stratification, free troposphere aerosol particles often remain in very thin altitude layers, on the scale of hundred meters (Stone et al. 2010). The vertical and horizontal distribution of Arctic aerosol is strongly influenced by local topography and wind (Dörnbrack et al. 2010). Therefore, measurements obtained at observation sites do not necessarily represent well the aerosol distribution of a larger area in complex terrain.

To analyse the potential of studying the lowest atmosphere with remote sensing technique, a lidar system was placed at the Zeppelin Mountain in Ny-Ålesund, Svalbard (Arctic), pointing downward into the Kongsfjord with an inclination of $3.2^{\circ}$. Such measurement geometry provided a vertical window from the surface to about $430 \mathrm{~m}$ altitude with a very high vertical resolution of $0.4 \mathrm{~m}$. To get such a high vertical resolution of the lowest $500 \mathrm{~m}$ of the atmosphere, it would be necessary to operate a tethered balloon or helicopter as platform, which are both very expensive and not very practical options. An aircraft would have to revisit the same location repeatedly to achieve this high resolution. Measurements with the lidar system on Zeppelin Mountain were performed on five days for several hours each day. The lidar needed an operator for switching the system on and off. Unattended measurements were not planned for this test campaign. The days when this concept was tested we encountered different atmospheric conditions that exemplify small scale boundary layer (BL) processes. In this study we present an analysis for two measurement days, 29 April 2007 and 1 May 2007. These days represent rather different conditions and diurnal evolution. 
The enhanced backscattering in the very lowest layers was intriguing and a cause for further investigation. The analyses include data from two additional lidar systems pointing in zenith direction, meteorological data and radiosonde profiles, as well as in situ aerosol observations conducted at the surface and at the Zeppelin Mountain (see Figs. 1 and 2 for geometry and locations).

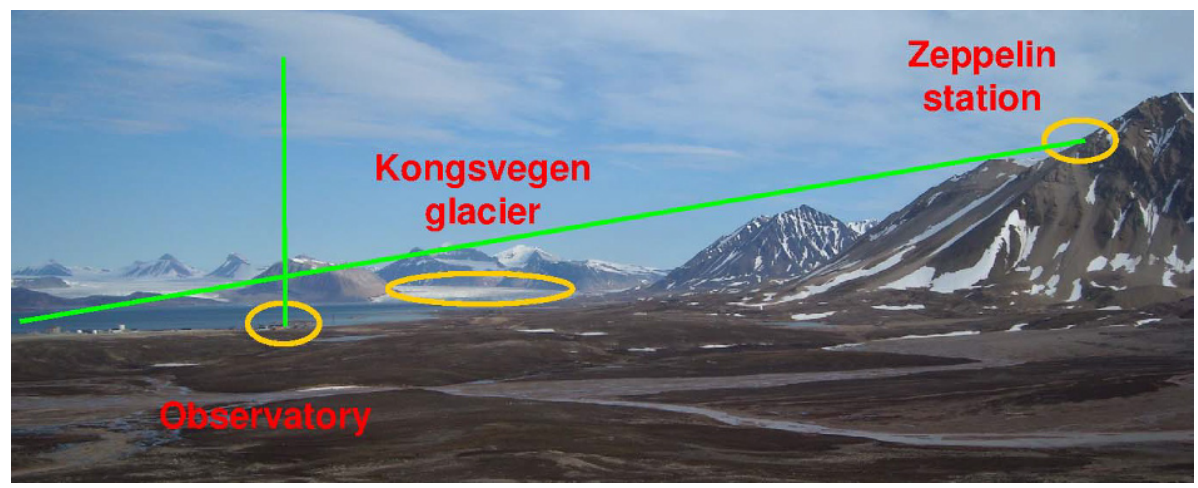

Fig. 1. Location and geometry of the lidar observations. The inclined AMALi was pointing downward towards the Kongsfjord from the station based on top of Zeppelin Mountain, the MPL and KARL lidars are routinely operated vertically upward from the atmospheric AWIPEV observatory in Ny-Ålesund. The picture was taken from a location NW of Ny-Ålesund in the direction to the Kongsvegen glacier SE of Ny-Ålesund. Courtesy of Marcus Schumacher.

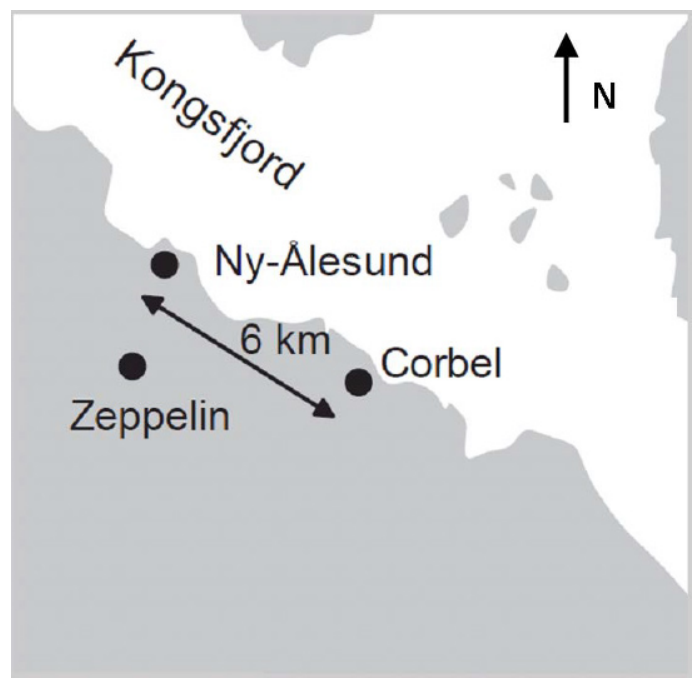

Fig. 2. Locations of the lidar systems (Zeppelin, Ny-Ålesund) and particle counters (Zeppelin, Corbel) in Svalbard, Arctic. 
The lidar and aerosol instruments are shortly introduced in Section 2. The meteorological background and the observations are presented in Section 3. A discussion of the data is provided in Section 4, and finally the conclusions are given in Section 5.

\section{INSTRUMENTS AND DATA}

\subsection{The lidar systems}

\section{Airborne Mobile Aerosol Lidar (Zeppelin station)}

The lidar system deployed on Zeppelin Mountain was the Airborne Mobile Aerosol Lidar (AMALi, Stachlewska et al. 2010). It uses a Nd:YAG laser emitting at the wavelengths 355 and $532 \mathrm{~nm}$; the latter is detected in both parallel and perpendicular polarization direction relative to the emitted pulses. The depolarization ratio allows to discriminate the shape of the scattering particles ( $\mathrm{Pal}$ and Carswell 1973), i.e., to distinguish between spherical (water droplets, hygroscopic aerosol) and non-spherical particles (ice crystals, sea salt or dust particles). The system is optimized for airborne applications and has a short distance of incomplete overlap between the laser beam and the telescope, and a relatively wide field of view of $3.1 \mathrm{mrad}$. A large laser aperture is used due to eye safety considerations. For airborne applications, the lidar system is eye safe for a distance larger than $2100 \mathrm{~m}$ (Stachlewska et al. 2010). For the inclined lidar applications from the Zeppelin Mountain, it had to be ensured that no air traffic was present.

The AMALi was operated from the laboratory building located on the Zeppelin Mountain. The lidar was lying on its side and slightly inclined downward at an angle of $3.2^{\circ}$ to collect profiles of backscatter with a range resolution of $7.5 \mathrm{~m}$, corresponding to a vertical resolution of $0.4 \mathrm{~m}$ for the applied inclination angle. In this paper we present AMALi lidar data in the backscatter ratio quantity, defined as the ratio of the total backscatter coefficient (molecular Rayleigh scattering and aerosol scattering) to the molecular Rayleigh scattering coefficient. Typical values for backscatter ratios at the clean Arctic site Ny-Ålesund are around 1.1 to 1.2 for $532 \mathrm{~nm}$ wavelength (Hoffmann et al. 2009). The initial evaluation of the lidar data was done with the standard Klett algorithm (Klett 1985). In the inversion algorithm, a value of the backscatter has to be assumed at the far end of the lidar profile. In the following case studies, this boundary condition was set at $60-90 \mathrm{~m}$ altitude and varied iteratively in a way similar to the method of Stachlewska et al. (2010) to obtain values for the backscatter at the near end of the lidar profile. These had to be in agreement with the values obtained by the zenith-pointing measurements of the Koldewey Aerosol Raman Lidar (KARL, see below) for the overlapping altitudes, if available. Otherwise, a typical value of the backscatter ratio for the altitude of $400 \mathrm{~m}$ (1.3) was used for the iterative 
method. To ensure a signal-to-noise ratio larger than 7 at $532 \mathrm{~nm}$ wavelength down to the fjord, the data are averaged over the time interval of $5 \mathrm{~min}$. This results in a total error of the backscatter coefficient of $7 \times 10^{-7} \mathrm{~m}^{-1} \mathrm{sr}^{-1}$ at maximal range (worst condition).

\section{Koldewey Aerosol Raman Lidar (AWIPEV observatoy)}

The Koldewey Aerosol Raman Lidar (KARL), integrated at the atmospheric observatory of the French-German research station AWIPEV (Alfred Wegener Institute / Institut Paul Emile Victor) in Ny-Ålesund, measures aerosol, optically thin clouds and water vapor in the troposphere and aerosol in the stratosphere. In 2007 it consisted of a Spectra Nd:YAG laser emitting at the wavelengths 355,532 , and $1064 \mathrm{~nm}$ simultaneously at a pulse repetition frequency of $50 \mathrm{~Hz}$ and a power of about $10 \mathrm{~W}$ per wavelength. The telescope of $30 \mathrm{~cm}$ diameter with $0.83 \mathrm{mrad}$ field of view (FOV) shows a complete overlap with the emitted laser beam above $1.2 \mathrm{~km}$. It collects, apart from the mentioned elastic wavelengths $(532 \mathrm{~nm}$ also in perpendicular state of polarization), the molecular nitrogen Raman shifted lines at 387 and $607 \mathrm{~nm}$, as well as the water vapor lines at 407 and $660 \mathrm{~nm}$. For the lowest atmospheric layers, a smaller mirror of $11 \mathrm{~cm}$ diameter with $2.25 \mathrm{mrad}$ FOV was used, which shows complete overlap above an altitude of $500 \mathrm{~m}$. Below, in the nearfield-range, the backscatter coefficient was calculated by the ratio of the elastic $(532 \mathrm{~nm})$ to the inelastic $(607 \mathrm{~nm})$ return as pointed out by Ansmann et al. (1992). The usage of the ratio of the two lidar signals cancels out the influence of incomplete overlap so that effectively the backscatter coefficient can be derived down to $180 \mathrm{~m}$ altitude. Note that in this range (11 cm mirror), only the wavelengths 532, 607, and $660 \mathrm{~nm}$ were recorded. For this study only data from the $11 \mathrm{~cm}$ telescope were considered. More details about the system and its applications can be found in Ritter et al. (2004). The elastic lidar profiles were averaged to a resolution of $2 \mathrm{~min}$ and $7.5 \mathrm{~m}$. The error in the backscatter profiles is mainly determined by the application of a boundary condition (Ansmann et al. 1992) which possibly causes a constant shift of the backscatter ratio of about 0.05 times the Rayleigh backscattering $\left(<7 \times 10^{-8} \mathrm{~m}^{-1} \mathrm{sr}^{-1}\right)$. In comparison to that, the error in the backscatter due to noise in the data is much smaller, around $5 \times 10^{-9} \mathrm{~m}^{-1} \mathrm{sr}^{-1}$ in $2 \mathrm{~km}$ altitude, and decreases towards the ground.

\section{Micro Pulse Lidar (AWIPEV observatory)}

The micro pulse lidar (MPL) is a compact and eye-safe lidar system for the continuous acquisition of long-term data of particle backscatter profiles (Spinhirne 1993) maintained by the base personnel of AWIPEV. The MPL in Ny-Ålesund is operated by the Japanese National Institute of Polar Research (NIPR) as one of the Micro-Pulse Lidar Network (MPLNET, Welton 
et al. 2001) sites in the Arctic. The system consists of a Nd:YLF laser with a wavelength of $523.5 \mathrm{~nm}$, a signal control unit, a Schmidt-Cassegrain telescope with $20 \mathrm{~cm}$ diameter, and a computer for data acquisition. The data are acquired from $60 \mathrm{~m}$ to $60 \mathrm{~km}$ with a vertical resolution of $30 \mathrm{~m}$ and a temporal average of $1 \mathrm{~min}$. The laser pulses are emitted vertically through a glass window. Data losses usually only occur when the window is covered with snow, which required to be removed manually. We use here the normalized relative backscatter, which is the range corrected signal divided by the transmitted laser pulse energy (Campbell et al. 2002). As we use the MPL lidar only qualitatively for obtaining an overview of the cloud situation, the backscatter coefficient with error bars was not calculated.

\subsection{Aerosol particle observations}

\section{Zeppelin station}

The Zeppelin station is situated on the Zeppelin Mountain at $474 \mathrm{~m}$ altitude above sea level. From a pool of many observations conducted at this station we have chosen data from three sets of in situ instruments for this study. The total number density was observed using condensation particle counters (CPC). The TSI Inc. CPC Model 3025 with the lower detection limit of $3 \mathrm{~nm}$ diameter and Model 3010 for particles larger than $10 \mathrm{~nm}$ diameter were used. By differentiating data from these two instruments, number density for very small particles, between 3 and $10 \mathrm{~nm}$, can be obtained. The third instrument was a custom built DMPS (Differential Mobillity Particle Sizer) which provides a size distribution for particles in the size range 10 to $800 \mathrm{~nm}$ every $10 \mathrm{~min}$ (typically the data rate is reduced to hourly averages). The instruments listed above are operated routinely at the Zeppelin station by the Department of Applied Environmental Science (ITM) at Stockholm University.

\section{Corbel station}

At the Corbel station, located $6 \mathrm{~km}$ in linear distance from the observatory on Zeppelin Mountain and only $5 \mathrm{~m}$ above mean sea level, a condensation particle counter was operated by the Korea Polar Research Institute (KOPRI). Here the TSI Inc. CPC Model 3776 with a lower detection limit for particles of a diameter of $2.5 \mathrm{~nm}$ was used.

\subsection{Meteorological observations}

At the AWIPEV observatory in Ny-Ålesund and at Zeppelin station, standard meteorological instruments are used for continuous monitoring of the meteorological parameters temperature, humidity, pressure, and wind. From the AWIPEV observatory, a Vaisala RS90 radiosonde is launched daily. 


\section{OBSERVATIONS}

\subsection{Meteorological situation}

During the time period between the end of April and the beginning of May 2007, the weather in Ny-Ålesund was determined by a high pressure system centred at the Shetland Islands. This resulted in low wind speed, with general air flow direction from the north and north east. The topography of the Kongsfjord and the surrounding glaciers is very important for the local wind conditions near Ny-Ålesund and generally in Svalbard (Sandvik and Furevik 2002). During the time period of our investigation the fjord was ice free and constituted a local source of moisture.

\subsection{Case I: Boundary layer structure on 29 April 2007}

As an overview of the cloud situation, we used the MPL data. On 29 April 2007, the MPL lidar observed optically thick low-level clouds up to an altitude of about $1 \mathrm{~km}$. The low-level cloud appeared around 06:00 UTC in the morning and lasted almost the entire day. For the majority of the time, the cloud was optically thick and attenuated the laser beam (see Fig. 3). The inclined AMALi lidar measurements from Zeppelin Mountain show that the backscatter ratio was exceeding background values of around 1.3 up to an altitude of about $200 \mathrm{~m}$ between 10:00 and 12:30 UTC (Fig. 4). From 10:30 to 11:00 UTC, the backscatter ratio was further enhanced throughout the column domain.

Directly above the Kongsfjord, a shallow layer of enhanced backscatter was observed (Fig. 4). This layer had a vertical depth of about $25 \mathrm{~m}$ and a sharp upper edge. The backscatter ratio within this layer showed values

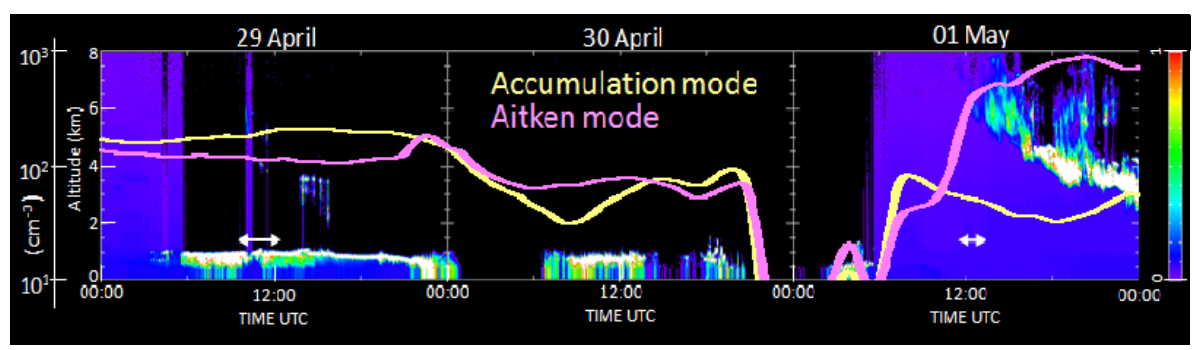

Fig. 3. The MPL lidar measurements from 29 April to 1 May 2007 (color coded). The values of normalized relative backscatter at $523 \mathrm{~nm}$ from the surface up to $8 \mathrm{~km}$ altitude. The DMPS measurements recorded at Zeppelin station are superimposed with plots for the number of Aitken mode (10-100 nm diameter, pink) and accumulation mode (larger than $100 \mathrm{~nm}$, yellow) particles. The two white arrows indicate the time periods of the AMALi data. 
around 2.5, in some range/height bins even exceeding 3. As the depolarization ratio (not shown here) was not enhanced within this layer, we can say that the particles were spherical in shape.

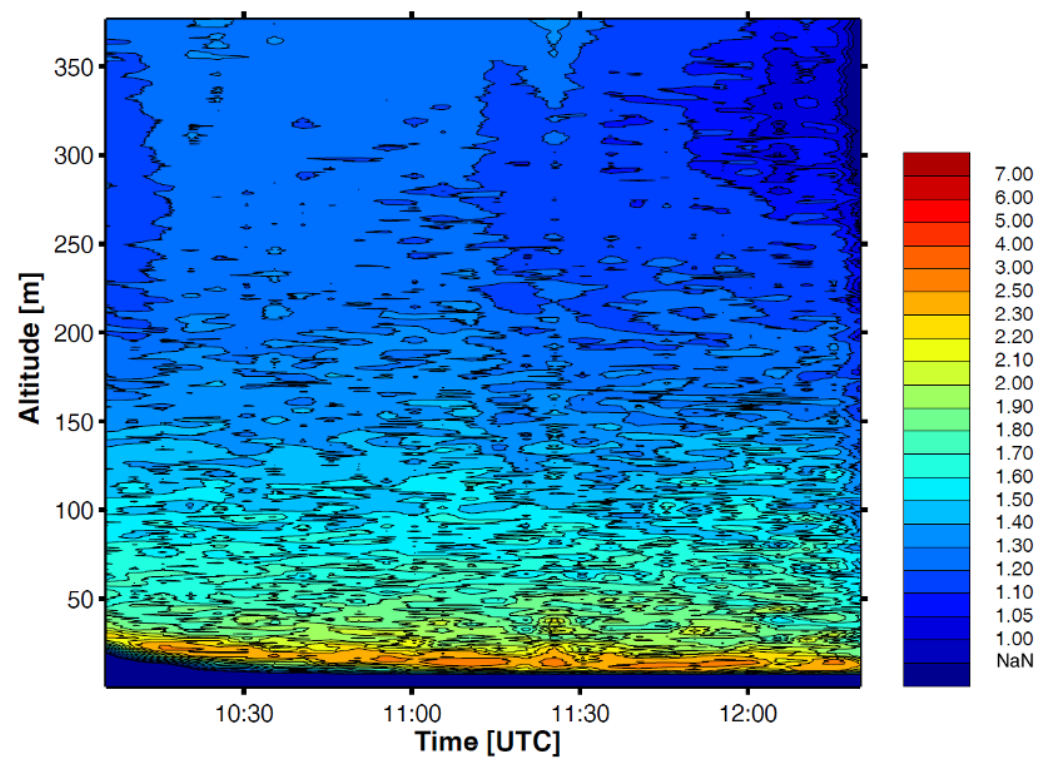

Fig. 4. Time series of the backscatter ratio measured with the inclined AMALi from Zeppelin station on 29 April 2007. Directly above Kongsfjord, a layer of enhanced backscatter extending only up to $25 \mathrm{~m}$ altitude is evident. The vertical resolution of the inclined lidar system is $0.4 \mathrm{~m}$. At the heights closest to the open water surface, the lidar data cannot be evaluated, indicated in the figure by not-a-number ( $\mathrm{NaN})$.

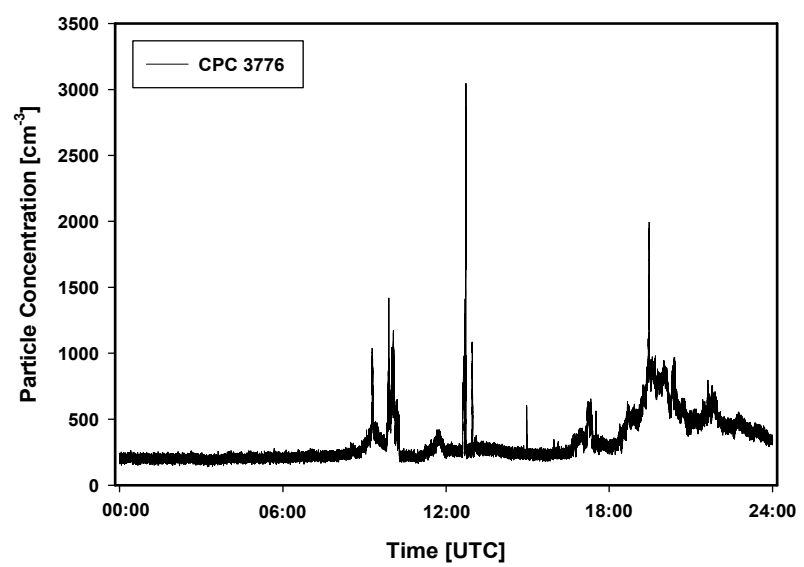

Fig. 5. The CPC particle concentration for particles with a diameter larger than $2.5 \mathrm{~nm}$ measured at ground-level at the Corbel station on 29 April 2007. 


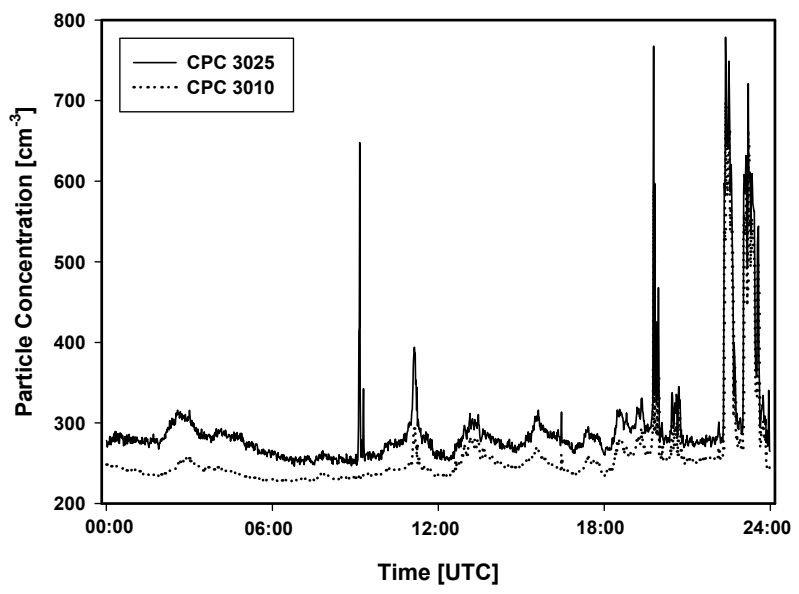

Fig. 6. The CPC particle concentration for particles with a diameter larger than $3 \mathrm{~nm}$ (CPC 3025) and larger than $10 \mathrm{~nm}$ (CPC 3010) measured at $474 \mathrm{~m}$ altitude at the Zeppelin station on 29 April 2007.
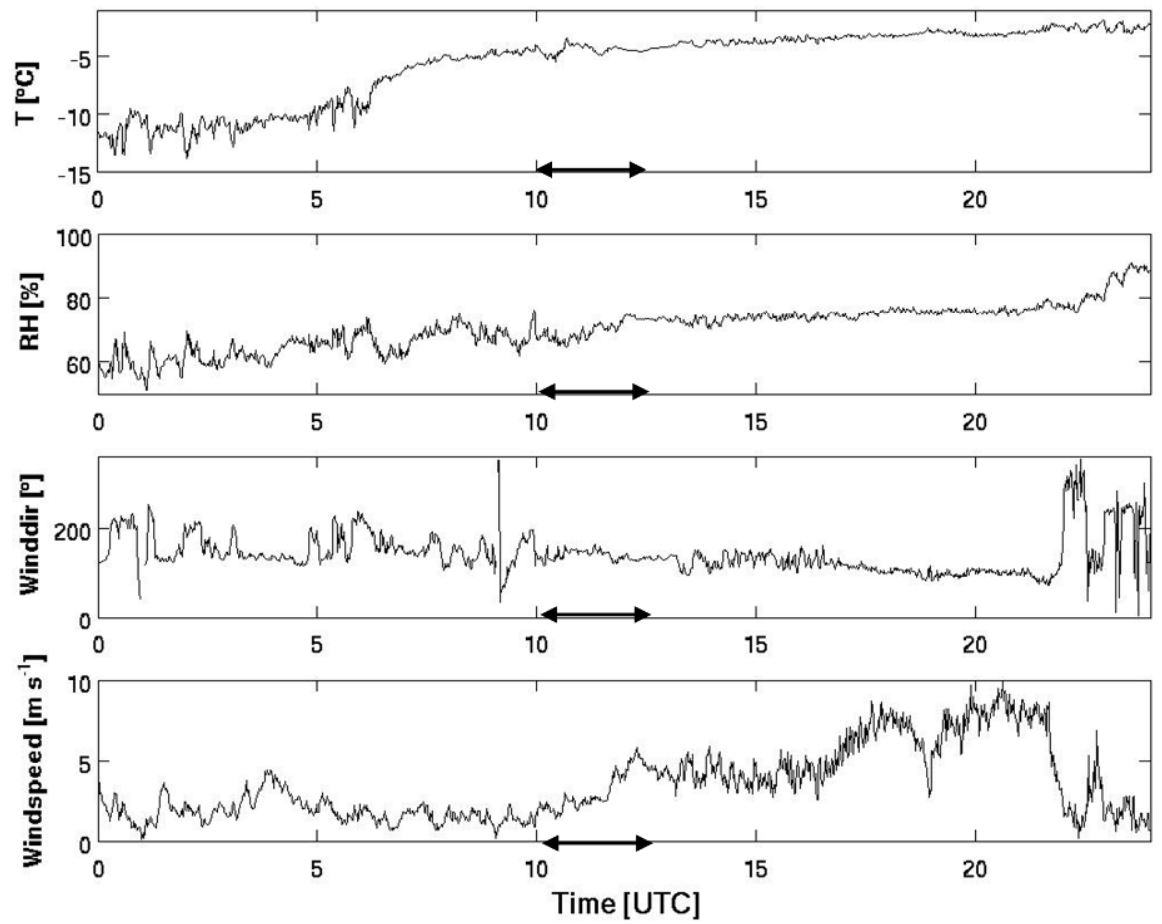

Fig. 7. Meteorological parameters measured at the AWIPEV observatory in Ny-Ålesund on 29 April 2007. The black arrows on the time axes represent the measurements with the inclined lidar system discussed here. 
The total aerosol number density measured with CPC, at both the Corbel and the Zeppelin station, indicated rather stable number densities between 200 and $300 \mathrm{~cm}^{-3}$ throughout most of the day with enhanced levels towards the evening (Figs. 5 and 6). This enhancement took place after the lidar observations in Fig. 4. The measurements of the two particle counters with different lower detection limit at the Zeppelin station do not detect the same particle concentrations (Fig. 6), which indicates a source of new particles that is large enough to compensate coagulation losses. In Figure 3 the DMPS data is super-imposed. The size distribution is divided into particles smaller than $0.1 \mu \mathrm{m}$ (Aitken mode) and particles larger than $0.1 \mu \mathrm{m}$ (Accumulation mode). On 29 April, the Accumulation mode particles show a weak increase whereas the Aitken mode particles show a weak decrease. Overall there are small changes besides at the end of the day.

The temporal evolution of meteorological parameters at the ground level in Ny-Ålesund (see Fig. 7) shows overall small changes. The temperature
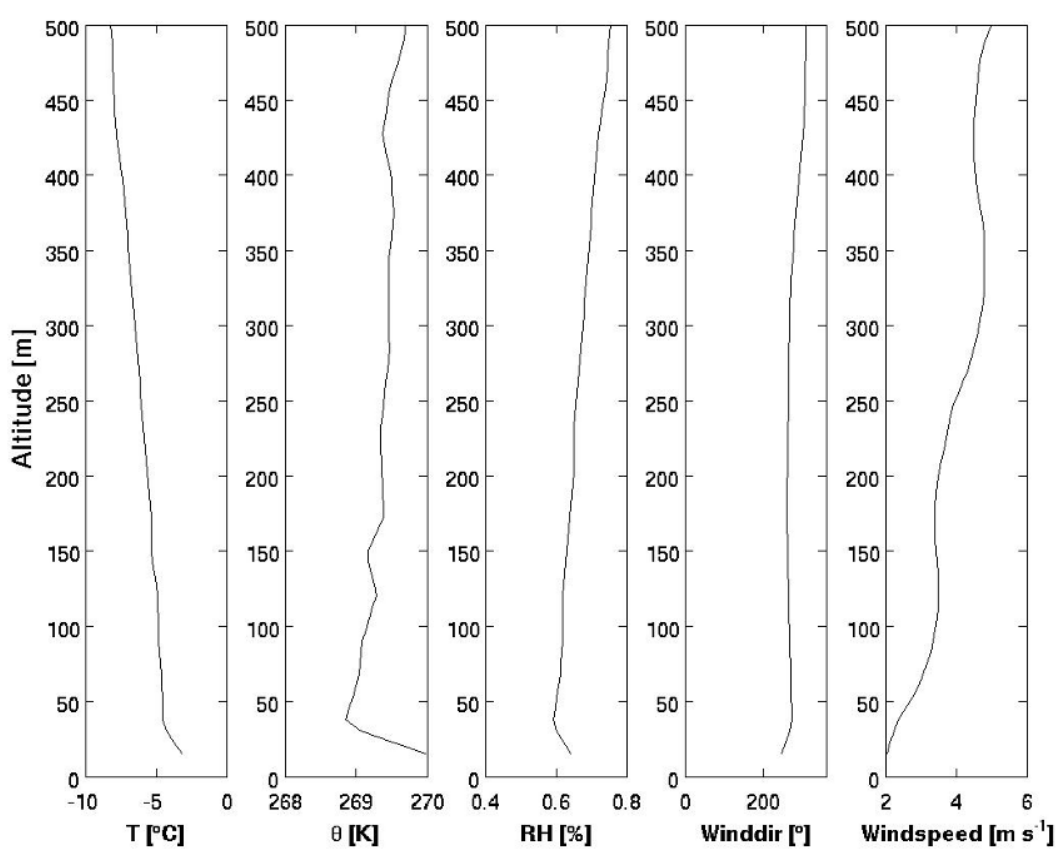

Fig. 8. Radiosonde profiles obtained from Ny-Ålesund on 29 April 2007 at 11:00 UTC: temperature, potential temperature, relative humidity, wind direction, and wind speed. The highly backscattering structure observed simultaneously in the lowest $25 \mathrm{~m}$ above the fjord is not represented in these profiles. There is neither a temperature inversion nor a strong increase of the humidity in the lowest $25 \mathrm{~m}$. The potential temperature is decreasing in the lowest $40 \mathrm{~m}$, indicating an unstable atmosphere. 
$\left(-5\right.$ to $\left.-3{ }^{\circ} \mathrm{C}\right)$, relative humidity $(65$ to $75 \%)$, and wind speed $\left(2.5\right.$ to $\left.5 \mathrm{~m} \mathrm{~s}^{-1}\right)$ increase only slightly from morning to afternoon. However, the vertical profile of the radiosonde (Fig. 8) shows a very significant change in the temperature in the lowest $40 \mathrm{~m}$. The lapse rate there corresponds to approximately $-5 \mathrm{~K} / 100 \mathrm{~m}$. This indicates a very unstable layer. Above this shallow layer the lapse rate is about $-1.5 \mathrm{~K} / 100 \mathrm{~m}$, which is still characteristic for unstable conditions. The potential temperature, $\theta$, presented in Fig. 8 emphasizes this vertical structure. Given the strongly unstable layer near the surface, the atmosphere in the altitude domain of the AMALi lidar most likely would also be mixed by so called non-local features, not captured by the sounding. An atmosphere presenting a near neutral profile can still have significant updrafts and downdrafts.

The meteorological measurements at Zeppelin Mountain recorded a temperature of around $-9{ }^{\circ} \mathrm{C}$, and a relative humidity increasing from 70 to $80 \%$ on 29 April 2007. The wind speed at that altitude was $2-3 \mathrm{~m} \mathrm{~s}^{-1}$ from the south. However, wind directions measured at the Zeppelin station should be taken with caution as it is affected by the mountain. It is also likely that wind speed and perhaps even temperature will be affected.

\subsection{Case II: Boundary layer structure on 1 May 2007}

The MPL lidar showed low level clouds between 04:00 and 08:00 UTC on 1 May 2007 (Fig. 3). In the afternoon, a cirrus cloud became apparent at an altitude of $6 \mathrm{~km}$ and remained visible for the rest of the day. At 17:00 UTC lower level clouds appeared at $4 \mathrm{~km}$ and descended to $3 \mathrm{~km}$ altitude by the end of the day.

The inclined AMALi lidar observations indicated a strongly backscattering layer on 1 May 2007 (see Fig. 9). In contrast, the atmosphere above the boundary layer had a lower backscatter ratio. The boundary layer altitude, defined here as the altitude with the largest vertical gradient of the backscatter observed with lidar, decreased during the day. In the morning (09:00 UTC, not shown) the strongly backscattering layer extended up to $474 \mathrm{~m}$ a.s.1., corresponding to the altitude of Zeppelin Mountain where the observatory is located. During the day, this strongly backscattering near surface layer was reduced. We interpret the top of the strongly backscattering layer as the $\mathrm{ABL}$ height. It was observed at an altitude of $350 \mathrm{~m}$ at 11:30 UTC, and at $250 \mathrm{~m}$ at 13:00 UTC (Fig. 9).

Zenith lidar measurements with KARL showed similar vertical and temporal backscatter pattern as the AMALi observations; compare Figs. 9 and 10. The decrease of the backscatter ratio, especially around $300 \mathrm{~m}$ between 12:00 and 13:00 UTC was also captured by this instrument. The change is less pronounced with increasing altitude. Above $600 \mathrm{~m}$ the backscatter 


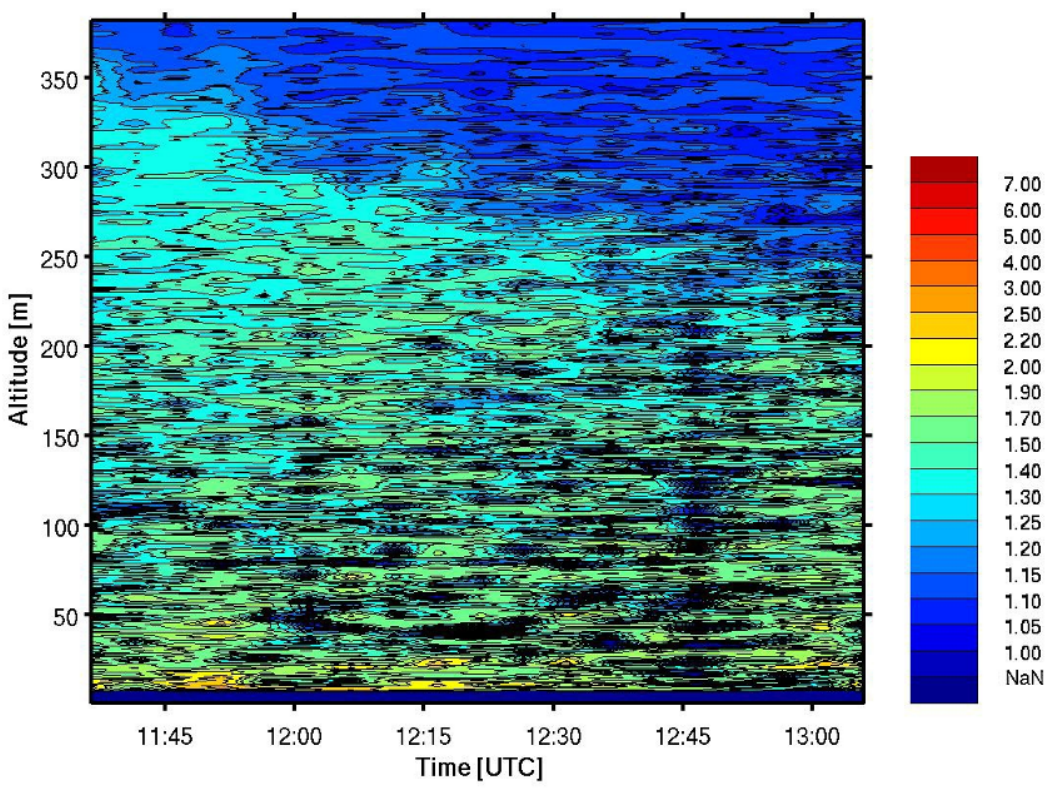

Fig. 9. Backscatter ratio profiles obtained between 11:30 and 13:15 UTC by the inclined AMALi lidar from Zeppelin station above Kongsfjord on 1 May 2007. The top of the highly reflecting boundary layer is decreasing from about $350 \mathrm{~m}$ at 11:30 to about $250 \mathrm{~m}$ at 13:15.

remains constant. However, the AMALi data present much greater detail in the boundary layer.

The temporal evolution of the total aerosol number density measured with CPC at the Zeppelin and Corbel stations is significantly different than in Case I. Zeppelin data (Fig. 11) present very low and variable data (not seen in the figure due to the linear presentation), often below $10 \mathrm{~cm}^{-3}$, for the beginning of the day. From around 09:00 UTC the number density increases rapidly to reach values around $4000 \mathrm{~cm}^{-3}$ at midday. The particle concentrations stabilize in the afternoon and decrease only in the evening after 21:00 UTC. Unfortunately, the aerosol data available from the Corbel station (Fig. 12) cover only the second part of the day. Nevertheless, the temporal evolution and overall number densities match well over the concurrent observation period. The number density between 10:00 and 13:00 UTC is about two times higher at Corbel than at the Zeppelin station. From 13:00 UTC and towards the end of the day concentrations decrease to $5000 \mathrm{~cm}^{-3}$. The differences between the concentrations obtained at the two stations can be partly explained by the different detection limits. The DMPS data (Fig. 3) are also very different from Case I. Here, like in the CPC data, the two modes begin with very low values during the first part of the day and 


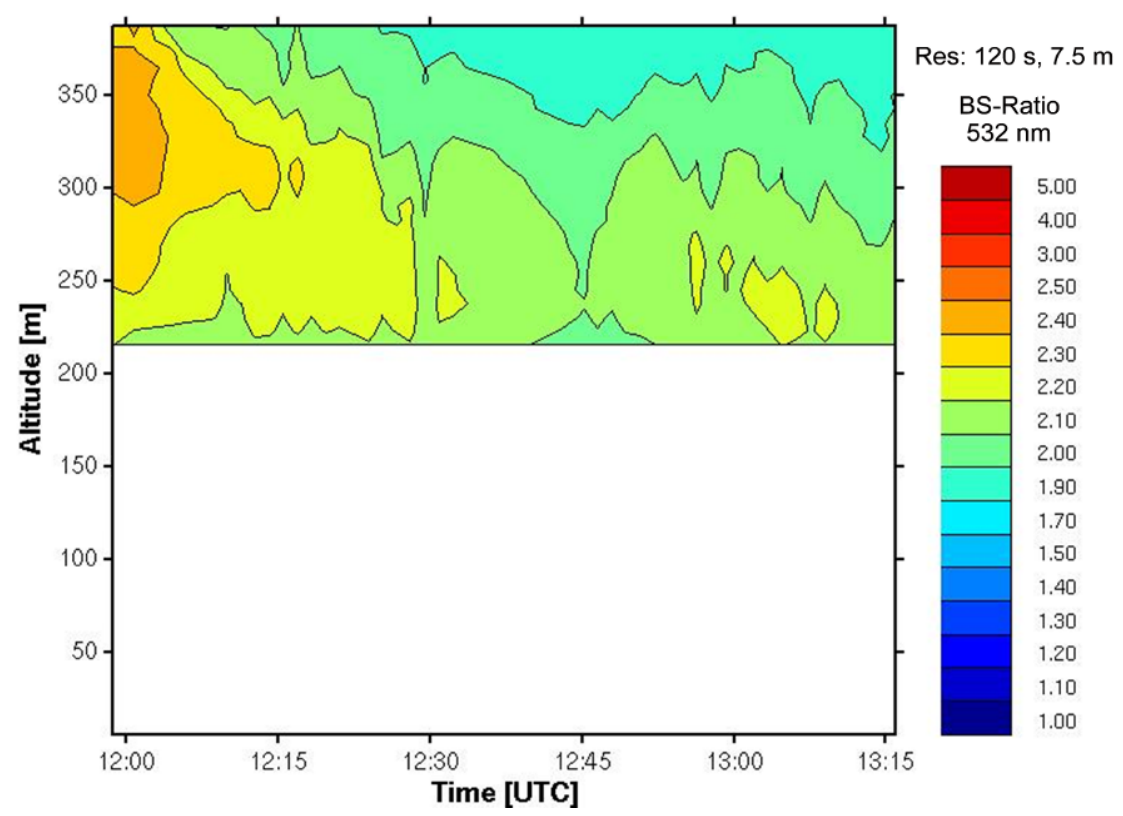

Fig. 10. Backscatter ratio observed by the KARL lidar simultaneously with the AMALi inclined lidar between 12:00 and 13:15 UTC in Ny-Ålesund on 1 May 2007. A decrease of the backscatter ratio with time in the lowest $400 \mathrm{~m}$ was observed by this lidar system as well. Below around $200 \mathrm{~m}$, no data are available due to incomplete overlap of the laser beam and telescope field of view.

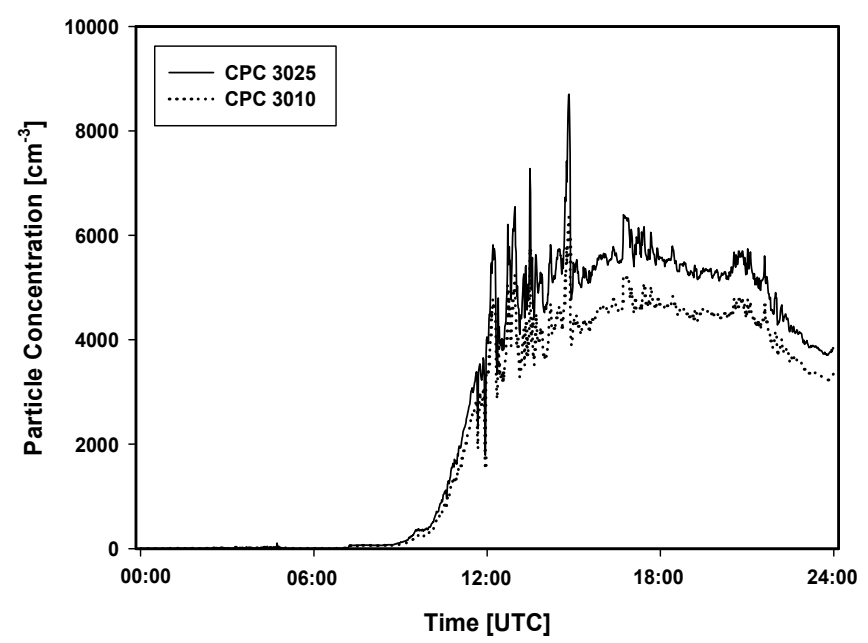

Fig. 11. Particle concentration for particles with a diameter larger than $3 \mathrm{~nm}$ (CPC $3025)$ and larger than $10 \mathrm{~nm}$ (CPC3010) measured at $475 \mathrm{~m}$ altitude (Zeppelin station) on 1 May 2007. 


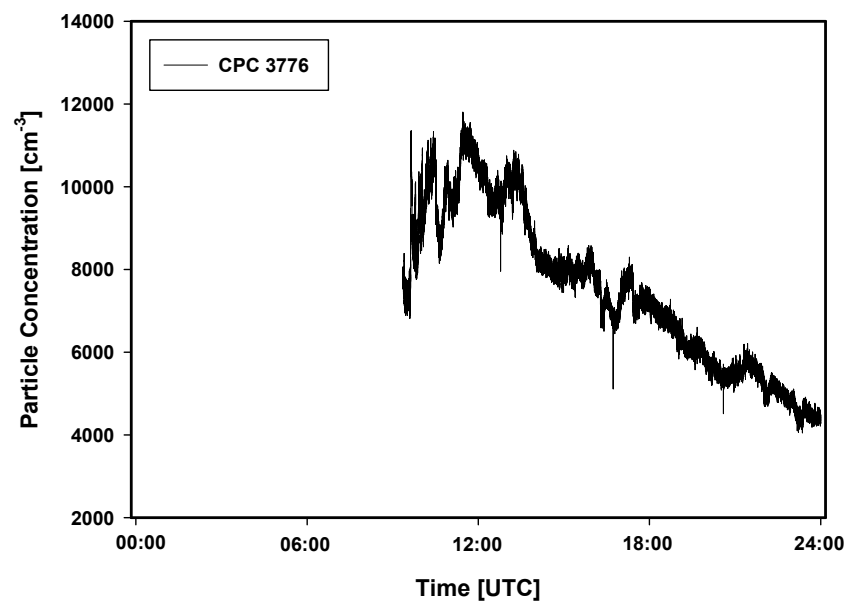

Fig. 12. Particle concentration for particles with a diameter larger than $2.5 \mathrm{~nm}$ measured at ground-level Corbel station on 1 May 2007.
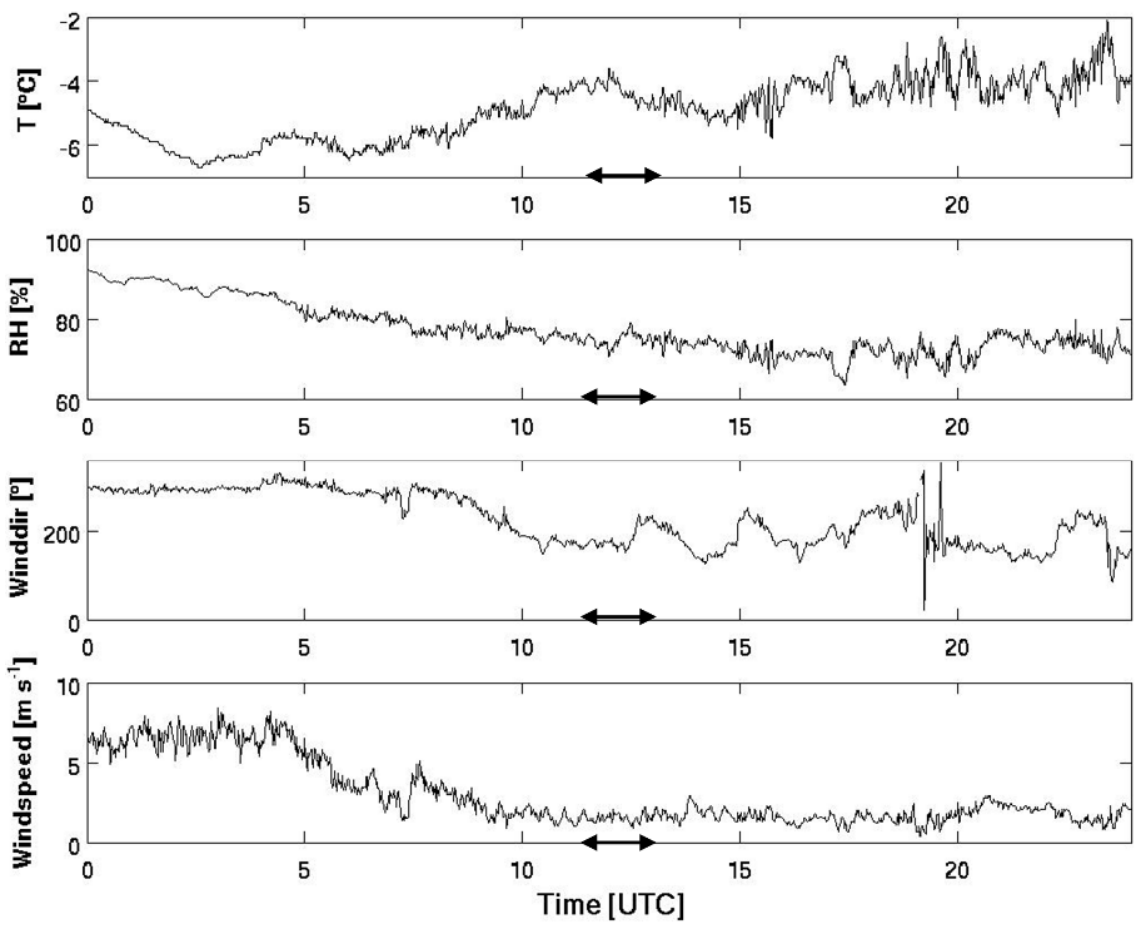

Fig. 13. Meteorological parameters measured at the AWIPEV observatory in Ny-Ålesund on 1 May 2007. The black arrows on the time axes represent the measurements with the inclined lidar system discussed here. 
after around 06:00 UTC both modes increase rapidly. The Aitken mode continues to increase to stabilize only in the afternoon. The Accumulation mode reaches a maximum already around 08:00 UTC and later decreases slightly during the day and increases again to reach the next maximum at midnight.

The typical values of the meteorological data from the AWIPEV observatory in Ny-Ålesund on 1 May (Fig. 13) are not very different from the 29 April case. The temperature ranges between -4 and $-5^{\circ} \mathrm{C}$, relative humidity decreases slightly from 80 to $70 \%$, and the wind speed is on average $2 \mathrm{~m} \mathrm{~s}^{-1}$. However, the wind direction is not stable and flips from about 150 degrees (from 10:00 to 12:30 UTC) to 250 degrees (12:00 to 13:30 UTC), and back to 150 degrees (13:30 to 15:00 UTC). This can be expected with very low wind speeds. The vertical variation of the temperature at 11:00 UTC on this day is very different from Case I. The radiosonde temperature data (Fig. 14) show an overall stable lowest $500 \mathrm{~m}$ with two strong inversions, one around $40 \mathrm{~m}$ and one around $350 \mathrm{~m}$, which represents the top of the boundary layer. The vertical structure of the potential temperature shows the stabillity of the lowest atmosphere. At Zeppelin Mountain, the
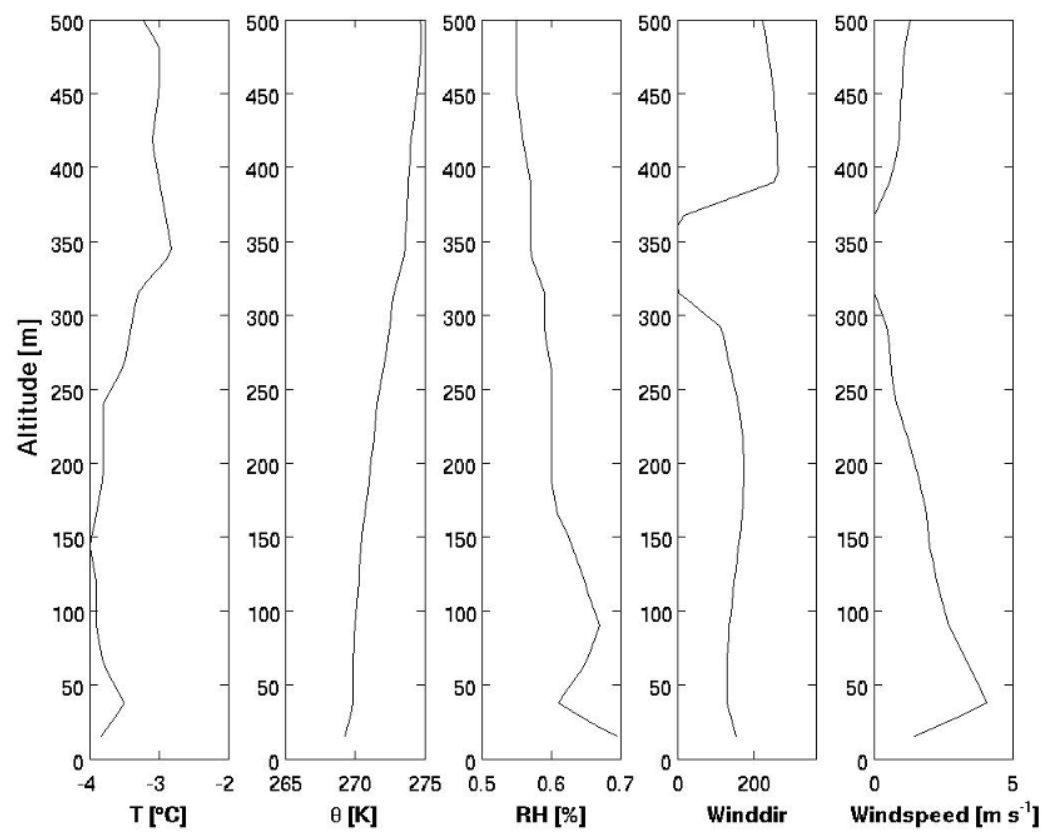

Fig. 14. Radiosonde profiles obtained in Ny-Ålesund on 1 May at 11:00 UTC: temperature, potential temperature, relative humidity, wind direction, and wind speed. The BL altitude indicated by lidar at around $350 \mathrm{~m}$ also shows changes in the meteorological parameters; A temperature inversion at $350 \mathrm{~m}$ and a minimum of wind speed with a change in wind direction at 300-350 m altitude. 
temperature was around $-8{ }^{\circ} \mathrm{C}$, and the relative humidity was around $95 \%$. The wind was low (around $1 \mathrm{~m} \mathrm{~s}^{-1}$ ) from north west.

\section{DISCUSSION}

Boundary layer clouds as on 29 April 2007 are frequently observed in Ny-Ålesund (Kupfer et al. 2006, Hoffmann et al. 2009). They give an indication of the upper edge for turbulent mixing. The direction of the wind recorded near the surface is typically along and out of the fjord but with altitude it becomes more variable (Beine et al. 2001). Three notable structures were observed with the lidars above the Kongsfjord that exemplify the potential use of highly resolved data over time and in the vertical dimension. These features were: (i) the low surface layer, (ii) the dynamically changing boundary layer, and (iii) the stable boundary layer.

The first feature is the layer of clearly enhanced backscatter in the lowest $25 \mathrm{~m}$ above the open water surface on 29 April 2007. This vertical dimension can be compared to the overall boundary layer depth of about $1 \mathrm{~km}$, based on the estimate of boundary layer cloud tops observed by the MPL lidar. The aerosol type in this layer is most probably sea salt particles. Further, this close to the water surface, the particles are usually expected to be hydrated and spherical. This is in agreement with the AMALi lidar depolarization values, which showed no increase in the lowermost layer. Hence, it is rather very humid air that mainly causes the strong backscatter. Change in the relative humidity (RH) from 50 to $90 \%$ can make the hygroscopic aerosol like sulfate grow about a factor of two in size (Fitzgerald 1975), resulting in a strong optical effect. If the humidity is closer to $100 \%$ this increase in size is even more dramatic. Open water is a source of water vapor that in the cold air increases the humidity near the surface and causes the aerosol to swell. The wind speed of $5 \mathrm{~m} \mathrm{~s}^{-1}$ recorded at $\mathrm{Ny}$-Ålesund is sufficient to enable sea salt production (O'Dowd and Smith 1993).

Based on the above, our initial hypothesis was that Arctic sea smoke (fog formed when water vapor is added to air much colder than the vapor's source) caused the observed lidar signal. This fog would be too thin optically to observe with a naked eye. With a relatively warm ocean surface and in the case of fairly low winds (only weak turbulence) it is plausible to have a thin subvisible cloud formed at a height just above the open water surface due to mixing of warmer moist air from near the surface and colder dry air from above. However, the humidity profiles of the radiosonde show that the conditions do not allow reaching supersaturation from mixing air. Even if the air above the fjord has a relative humidity of $100 \%$ and is a bit warmer than the temperature recorded at the AWIPEV observatory, a fog could not form. The estimation of the lapse rate out of the radiosonde data resulted in a value of 
$-5 \mathrm{~K} / 100 \mathrm{~m}$ (the potential temperature is decreasing by $1 \mathrm{~K}$ in the lowest $50 \mathrm{~m}$; Fig. 8) which means that the lowest $50 \mathrm{~m}$ are very unstable, the conditions are probably even more unstable due to the warmer water surface over the fjord. This is consistent with the vapor flux as indicated by the RH profile. As the local wind direction during the observation period was from the south east (Fig. 7), along and out of the fjord (Fig. 2), the meteorological conditions at $\mathrm{Ny}$-Ålesund cannot be compared directly with the conditions above the fjord. At the observation site the ABL is further modified by orographic effects. Mountains influence the wind flow field (Beine et al. 2001, Argentini et al. 2003, Kilpeläinen and Sjöblom 2010) and may increase or decrease the turbulent activity created by wind shear (Dörnbrack et al. 2010). Changes of the boundary layer properties occur on small spatial scales. The meteorological measurements at the AWIPEV observatory, although located at the ground, do not indicate enhanced relative humidity, and therefore probably miss this important structure above the nearby fjord.

The second interesting observation is the behavior of aerosol concentration in the boundary layer on 29 April 2007. The aerosol load above an altitude of about $150 \mathrm{~m}$ is changing on the time scale of $30 \mathrm{~min}$. With the wind speed of $5 \mathrm{~m} \mathrm{~s}^{-1}$ determined by the radiosonde and at the meteorological measurement sites, this corresponds to a horizontal length of $10 \mathrm{~km}$. The characteristic scale is in the size range of convective cells (Atkinson and Zhang 1996). There is also evidence of dynamics in the Zeppelin CPC data with a period of approximately one hour, similar as in the lidar data.

The third distinct phenomenon observed in the boundary layer occurs on 1 May 2007. Here, in contrary to the dynamic boundary layer structure which was observed on 29 April, the situation changes as the stability increases during the observation period. An increasing solar radiation after the dissolving of the morning low-level clouds most likely leads to convective mixing of the boundary layer. A temperature inversion, which is evident in the radio sounding (Fig. 14), prohibited further vertical exchange with the air above. Even if the surface winds are not too different from those observed on 29 April (radiosonde measured differences below $2 \mathrm{~m} \mathrm{~s}^{-1}$ ), the large particles remain confined to the boundary layer. These efficient cloud condensation nuclei are not transported up as hypothesized for the case on 29 April. There is sunlight in the morning and less surface area (only few particles in the Accumulation mode) to condense gases on, which results in the formation of new particles. The difference in particle concentration with lower threshold diameter of 3 and $10 \mathrm{~nm}$ provides evidence of new particle formation (Kulmala et al. 2004). The number of Aitken mode particles recorded by the CPC on Zeppelin Mountain increased (Fig. 3), which indicates enough condensable material available to make the newly formed particles grow. At sea level above land (Corbel station), after the midday maximum 
the total number concentration decreases during the day, which indicates that the sink for small particles is larger than the source and hence that the particles are lost by coagulation and deposition. From the AMALi data we note that the optically active aerosols in the BL are suppressed vertically. The integral optical depth changes less than the geometric depth of the BL. Over 1 hour and $15 \mathrm{~min}$ the BL subsided about $100 \mathrm{~m}$, which is equivalent to a few centimeters per seconds and consistent with large scale subsidence. We hypothesize that on 1 May 2007 we observed boundary layer drying up from the top. In the morning the boundary layer was very moist and the aerosol within it contained a lot of water. With the cloud clearing, dryer air pressing from above was mixed into the BL. The temperature increased, which results in the aerosol repositing the condensed water to the vapor phase. As the smaller particles are less effective scatterers of laser radiation, the lidar signals get lower. Without an efficient turbulent mixing, no wet and large particles originated near the surface can be transported upwards to replace the drying particles.

\section{CONCLUSIONS}

The two examples discussed in this paper demonstrate a great potential for conducting boundary layer research using the inclined lidar pointing down towards the fjord. In the future, remote sensing aerosol observations could be combined with flux measurements of aerosols related to marine sources, e.g., by combining in situ measurements near the fjord, at the Zeppelin station and using an airborne lidar overflying this area.

The observations of enhanced backscatter above the fjord surface, which so significantly differ from meteorological and in situ measurements above land, demonstrate the small-scale differences caused by local orography. Therefore, deductions based on the climatology of single observation sites have to be interpreted carefully. In such cases it is essential to verify how representative is the particular measurement site for the surrounding area.

As shown for the two cases, lidar measurements can remotely identify aerosol and help to interpret atmospheric processes above the open water, like turbulent mixing. Further, presented lidar measurements served to deduce the evolution of meteorological parameters, like the altitude variations or stability of the boundary layer. The extremely high vertical resolution, gained as a result of the geometry of the observations, evidenced a very patchy small scale structure of high and low backscatter ratios. The monitoring of these parameters above open water provides new insights in atmospheric processes which are of importance for better understanding the ABL and can be used for modeling activities. 
Acknowledgements. The authors would like to thank the staff of the AWIPEV station for the support with the portable lidar measurements, the Alfred Wegener Institute for providing the meteorological data, the Swedish Environmental Protection Agency for supporting the aerosol measurements at the Zeppelin station. We would like to thank Marcus Schumacher for the photo illustrating the lidar geometry. We thank Ove Hermansen for discussion about the meteorological data of Zeppelin station. Thanks also to the personnel at the Sverdrup station for help in mounting the AMALi system at the Zeppelin station. Y.J. Yoon thanks to the support from KOPRI project "Korea Arctic Multidisciplinary Program (PP10090)". Finally, we acknowledge two anonymous reviewers who helped to improve the manuscript with their detailed comments.

\section{References}

Ansmann, A., U. Wandinger, M. Riebesell, C. Weitkamp, and W. Michaelis (1992), Independent measurement of extinction and backscatter profiles in cirrus clouds by using a combined Raman elastic-backscatter lidar, Appl. Opt. 31, 33, 7113-7113, DOI: 10.1364/AO.31.007113.

Argentini, S., A.P. Viola, G. Mastrantonio, A. Maurizi, T. Georgiadis, and M. Nardino (2003), Characteristics of the boundary layer at Ny-Ålesund in the Arctic during the ARTIST field experiment, Ann. Geophys. 46, 2, 185-196.

Atkinson, B.W., and J.W. Zhang (1996), Mesoscale shallow convection in the atmosphere, Rev. Geophys. 34, 4, 403-431, DOI: 10.1029/96RG02623.

Beesley, J.A., C.S. Bretherton, C. Jakob, E.L. Andreas, J.M. Intrieri, and T.A. Uttal (2000), A comparison of cloud and boundary layer variables in the ECMWF forecast model with observations at Surface Heat Budget of the Arctic Ocean (SHEBA) ice camp, J. Geophys. Res. 105, D10, 1233712349, DOI: 10.1029/2000JD900079.

Beine, H.J., S. Argentini, A. Maurizi, G. Mastrantonio, and A. Viola (2001), The local wind field at Ny-Ålesund and the Zeppelin mountain at Svalbard, Meteorol. Atmos. Phys. 78, 1-2, 107-113, DOI: 10.1007/s007030170009.

Brümmer, B., B. Busack, H. Hoeber, and G. Kruspe (1994), Boundary-layer observations over water and Arctic sea-ice during on-ice air flow, Bound.-Lay. Meteorol. 68, 1-2, 75-108, DOI: 10.1007/BF00712665.

Campbell, J.R., D.L. Hlavka, E.J. Welton, C.J. Flynn, D.D. Turner, J.D. Spinhirne, V.S. Scott, and I.H. Hwang (2002), Full-time, eye-safe cloud and aerosol lidar observation at atmospheric radiation measurement program sites: Instruments and data processing, J. Atmos. Oceanic Technol. 19, 4, 431-442, DOI: 10.1175/1520-0426(2002)019<0431:FTESCA>2.0.CO;2. 
Curry, J.A., E.E. Ebert, and G.F. Herman (1988), Mean and turbulence structure of the summertime Arctic cloudy boundary layer, Q. J. Roy. Meteor. Soc. 114, 481, 715-746, DOI: 10.1002/qj.49711448109.

Dare, R.A., and B.W. Atkinson (2000), Atmospheric response to spatial variations in concentration and size of polynyas in the Southern ocean sea-ice zone, Bound.-Lay. Meteorol. 94, 1, 65-88, DOI: 10.1023/A:1002442212593.

Dörnbrack, A., I.S. Stachlewska, C. Ritter, and R. Neuber (2010), Aerosol distribution around Svalbard during intense easterly winds, Atmos. Chem. Phys. 10, 4, 1473-1490, DOI: 10.5194/acp-10-1473-2010.

Fitzgerald, J.W. (1975), Approximation formulas for the equilibrium size of an aerosol particle as a function of its dry size and composition and the ambient relative humidity, J. Appl. Meteor. 14, 6, 1044-1049, DOI: 10.1175/15200450(1975)014<1044:AFFTES>2.0.CO;2.

Hoffmann, A., C. Ritter, M. Stock, M. Shiobara, A. Lampert, M. Maturilli, T. Orgis, R. Neuber, and A. Herber (2009), Ground-based lidar measurements from Ny-Ålesund during ASTAR 2007, Atmos. Chem. Phys. 9, 22, 9059-9081, DOI: 10.5194/acp-9-9059-2009.

Kilpeläinen, T., and A. Sjöblom (2010), Momentum and sensible heat exchange in an ice-free Arctic fjord, Bound.-Lay. Meteorol. 134, 1, 109-130, DOI: 10.1007/s10546-009-9435-x.

Klett, J.D. (1985), Lidar inversion with variable backscatter/extinction ratios, Appl. Opt. 24, 11, 1638-1643, DOI: 10.1364/AO.24.001638.

Kulmala, M., H. Vehkamäki, T. Petäjä, M. Dal Maso, A. Lauri, V.-M. Kerminen, W. Birmili, and P.H. McMurry (2004), Formation and growth rates of ultrafine atmospheric particles: a review of observations, J. Aerosol Sci. 35, 2, 143-176, DOI: 10.1016/j.jaerosci.2003.10.003.

Kupfer, H., A. Herber, and G. König-Langlo (2006), Radiation measurements and synoptic observations at Ny-Ålesund, Rep. Polar Res. 538, 75, http://epic.awi.de/Publications/Kup2006a.pdf.

O’Dowd, C.D., and M.H. Smith (1993), Physicochemical properties of aerosols over the Northeast Atlantic: Evidence for wind-speed-related submicron sea-salt aerosol production, J. Geophys. Res. 98, D1, 1137-1149, DOI: 10.1029/ 92JD02302.

Pal, S.R., and A.I. Carswell (1973), Polarization properties of lidar backscattering from clouds, Appl. Opt. 12, 7, 1530-1535, DOI: 10.1364/AO.12.001530.

Paluch, I.R., D.H. Lenschow, and Q. Wang (1997), Arctic boundary layer in the fall season over open and frozen sea, J. Geophys. Res. 102, D22, 25955-25971, DOI: $10.1029 / 97 J D 01563$.

Ritter, C., A. Kirsche, and R. Neuber (2004), Tropospheric aerosol characterized by a Raman lidar over Spitsbergen. In: Proc. 22nd Int. Laser Radar Conference, ILRC2004, ESA SP-561, 459-462. 
Sandvik, A.D., and B.R. Furevik (2002), Case study of a coastal jet at Spitsbergen Comparison of SAR- and model-estimated wind, Mon. Wea. Rev. 130, 4, 1040-1051, DOI: 10.1175/1520-0493(2002)130<1040:CSOACJ>2.0.CO;2.

Spinhirne, J.D. (1993), Micro pulse lidar, IEEE Trans. Geosci. Remote Sens. 31, 1, 48-55, DOI: 10.1109/36.210443.

Stachlewska, I.S., R. Neuber, A. Lampert, C. Ritter, and G. Wehrle (2010), AMALi - the Airborne Mobile Aerosol Lidar for Arctic research, Atmos. Chem. Phys. 10, 6, 2947-2963, DOI: 10.5194/acp-10-2947-2010.

Stone, R., A. Herber, V. Vitale, M. Mazzola, A. Lupi, R. Schnell, E. Dutton, P. Liu, S.-M. Li, K. Dethloff, A. Lampert, C. Ritter, M. Stock, R. Neuber, and M. Maturilli (2010), A three-dimensional characterization of Arctic aerosols from airborne Sun photometer observations; PAM-ARCMIP - April 2009, J. Geophys. Res. 115, D13203, DOI: 10.1029/2009JD013605.

Tjernström, M. (1999), Sensitivity of coastal atmospheric supercritical flow to ambient conditions, Tellus 55, 880-901.

Tjernström, M. (2005), The summer arctic boundary layer during the Arctic Ocean Experiment 2001 (AOE-2001), Bound.-Lay. Meteorol. 117, 1, 5-36, DOI: 10.1007/s10546-004-5641-8.

Tomasi, C., V. Vitale, A. Lupi, C. Di Carmine, M. Campanelli, A. Herber, R. Treffeisen, R.S. Stone, E. Andrews, S. Sharma, V. Radionov, W. von Hoyningen-Huene, K. Stebel, G.H. Hansen, C.L. Myhre, C. Wehrli, V. Aaltonen, H. Lihavainen, A. Virkkula, R. Hillamo, J. Ström, C. Toledano, V.E. Cachorro, P. Ortiz, A.M. de Frutos, S. Blindheim, M. Frioud, M. Gausa, T. Zieliński, T. Petelski, and T. Yamanouchi (2007), Aerosols in polar regions: A historical overview based on optical depth and in situ observations, J. Geophys. Res. 112, D16205, DOI: 10.1029/2007JD008432.

Treffeisen, R., P. Turnved, J. Ström, A. Herber, J. Bareiss, A. Helbig, R.S. Stone, W. Hoyningen-Huene, R. Krejci, A. Stohl, and R. Neuber (2007), Arctic smoke - aerosol characteristics during a record smoke event in the European Arctic and its radiative impact, Atmos. Chem. Phys. 7, 11, 3035-3053, DOI: $10.5194 / \mathrm{acp}-7-3035-2007$.

Vihma, T., J. Hartmann, and C. Lüpkes (2003), A case study of an on-ice air flow over the Arctic marginal sea-ice zone, Bound.-Lay. Meteorol. 107, 1, 189217, DOI: 10.1023/A:1021599601948.

Vogelmann, A.M., P.J. Flatau, M. Szczodrak, K.M. Markowicz, and P.J. Minnett (2003), Observations of large aerosol infrared forcing at the surface, Geophys. Res. Lett. 30, 1655, DOI: 10.1029/2002GL016829.

Welton, E.J., J.R. Campbell, J.D. Spinhirne, and V.S. Scott (2001), Global monitoring of clouds and aerosols using a network of micro-pulse lidar systems, SPIE Proc. Ser. 4153, 151-158.

Received 5 November 2010 Received in revised form 26 May 2011

Accepted 3 October 2011 